\title{
EDITORIAL
}

\section{A new phase at NPG Asia Materials}

\author{
NPG Asia Materials (2012) 4, e5; doi:10.1038/am.2012.9; published online 18 January 2012
}

$\mathrm{W}$ ith the current issue of Volume 4, NPG Asia Materials has entered a new phase in which it starts publishing original research articles in addition to review papers. This marks a further transformation of a publication, which was founded in 2008 upon the initiative of the Tokyo Institute of Technology and in close cooperation with NPG Nature Asia-Pacific in Tokyo. The initial aim was to increase the awareness of materials research being carried out in the Asia-Pacific region, which now contributes a substantial share of the global research output in the materials sciences. The journal began by publishing research highlights of papers coming from the region, and these were joined by review articles in 2009. During its short period of existence, the project succeeded in drawing attention to the quality and variety of materials science research in the Asia-Pacific, and in creating a sense of community among many of the scientists and engineers based in the region.

The new phase brings about a few changes. It will no longer be a region-orientated journal but will publish the best articles from around the world and across all disciplines of materials science. It will continue to increase its wide audience through quality publications and being hosted on http://www.nature.com as a member of the family of NPGs academic journals. It is also an online-only, fully open access journal making the content freely available to all researchers worldwide and ensuring maximum dissemination of the research output. Among the main benefits to authors are higher citation rates and the availability of publishing articles through a Creative Commons License. In addition, the journal is introducing Research Summaries-short, professionally written synopses of an article for general and specialist readers that NPG is publishing under a Creative Commons License. With appropriate attribution, authors and others can use, reuse, post and send Research Summaries to the increasing array of online fora and social networking sites.

As an academic journal it is run by academics-overseen by the founding editor Hideo Takezoe of Tokyo Institute of Technology, and managed by the Editor-in-Chief together with four Associate Editors. These are Hee Cheul Choi from Postech in the area of nanomaterials, Shutao Wang from the Institute of Chemistry CAS in the area of bio-related materials, Ikuyoshi Tomita from the

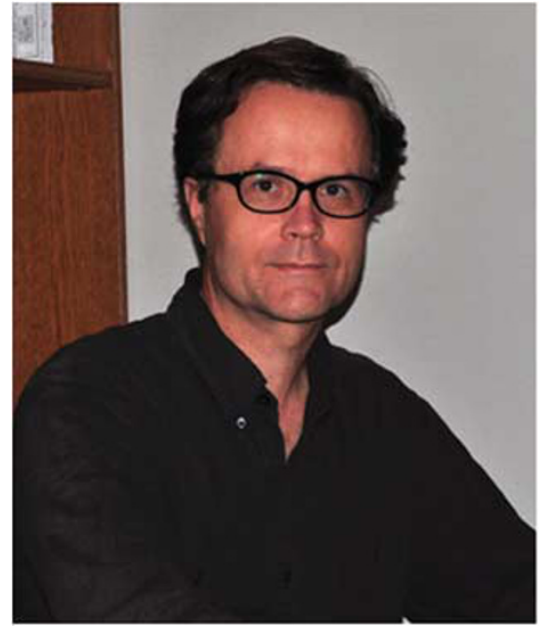

Tokyo Institute of Technology in the area of organic and polymer chemistry, and Tomoyasu Taniyama from the Tokyo Institute of Technology in the area of solid-state physics. All other areas are covered by the Editor-in-Chief. The journal will receive its first impact factor in 2012.

Here, I would like to invite you to read the review and original articles in the current collection of papers, which span all aspects of materials science, from DNA-based materials, to semiconducting nanoparticles, to chiral organic chemistry and to superconductivity. I also hope for your continued support of NPG Asia Materials as readers, as well as potential authors and reviewers.

$$
\begin{array}{r}
\text { Martin Vacha } \\
\text { Editor-in-Chief } \\
\text { Department of Organic and Polymeric Materials, } \\
\text { Tokyo Institute of Technology, Tokyo, Japan } \\
\text { E-mail: vacha.m.aa@m.titech.ac.jp }
\end{array}
$$

